\title{
JAES AÇEH
}

\section{Giresun İlindeki Balık Avlama Filosunun Teknik özellikleri}

\author{
Cengiz MUTLU ${ }^{1 *} \quad$ Cengaver Murad UNCUMUSAOĞLU ${ }^{1} \quad$ Bülent VEREP ${ }^{2}$ \\ 1* Giresun Üniversitesi, Fen Edebiyat Fakültesi, Biyoloji Bölümü, TR-28 200 Giresun, Turkey \\ ${ }^{1}$ Giresun Üniversitesi, Fen Edebiyat Fakültesi, Biyoloji Bölümü, TR-28 200 Giresun, Turkey \\ ${ }^{2}$ Recep Tayyip Erdoğan Üniversitesi, Su Ürünleri Fakültesi, Temel Bilimler Bölümü, Rize, Türkiye.
}

Öz: Bu çalışmada Giresun'da balıkçılık faaliyette bulunan avlama teknelerinin teknik özelliklerini saptamak üzere ilin Doğu Karadeniz klyısındaki ilçelerden seçim yapılmıştır. Bu seçime göre Piraziz, Bulancak, Merkez birinci grubu, Gülburnu ve Tirebolu ikinci grubu, Görele, Çavuşlu, Eynesil ilçeleri ise üçüncü grubu oluşturmuştur. Tabakalı tesadüfi örnekleme yöntemi ile anketler yapılarak balıkçı teknelerinin teknik özellikleri, yardımcı tekne özellikleri, ăg donanım özelikleri, avcllı gereçleri özellikleri ve mevcut sorunlar incelenerek çözüm önerileri ileri sürülmüştür.

Anahtar sözcükler: Giresun balıkçılığı, balıkçı profili, avlama filosu

\section{Technical Specifications of Fishing Fleet in Giresun Province}

\begin{abstract}
In this study, the provinces along the eastern Black Sea coast were selected to determine the technical characteristics of fishing vessels operating in Giresun. According to this election, Piraziz, Bulancak, Central first group, Gülburnu and Tirebolu second group, Relative, Çavuşlu, Eynesil district third group. Questionnaires were made by stratified random sampling method, and technical specifications of fishing boats, auxiliary boat characteristics, network equipment properties, hunting equipment characteristics and present problems were suggested and solution proposal was put forward.
\end{abstract}

Keywords: Giresun fishery, fisherman profile, fishing fleet

\section{GİRIŞ}

Türkiye balıkçılık sektörünün $\mathrm{AB}$ balıkçılık sektörü ile entegrasyonun da uygulamaların sağlıklı bir şekilde yürütülmesi ve önlemlerin başarılı olması için balıkçılık filosunun yapısı, fiziksel ve teknik özelliklerinin belirlenmesi gerekmektedir.

Avlama teknolojisindeki gelişmelere bağlı olarak av araçları, ağlar ve balık bulucu cihazların kullanımı hızlı bir şekilde artmaktadır. Buna bağlı olarak her gelişen yeni teknolojisi kullanarak yalnızca ekonomik fayda ve üretim artışı gibi hedefleri dikkate almak yanıltıcı olmaktadır. Su ürünleri avcılığında kullanılan ekipmanlar dizaynında seçici ve hedefe yönelik olarak organize yapılmalıdır. Ekipmanların standart hale getirilmesi çalışmalarına önem verilmelidir.

Balıkçılık, sadece üretim olarak değil bunun yanı sıra birçok alanda yarattığı istihdam nedeniyle ekonomiye yapmış olduğu katkılar nedeniyle önemli bir sektör haline gelmiştir (Mastracchio, 2007).
AB Ortak Balıkçılık Politikasına göre; Yapısal Politikalar hem diğer Birlik Politikaları ile Balıkçılık Politikasının birbirleriyle ilişkileri kuvvetli bir şekilde sağlanarak balıkçılara verilen destek artmalı. Sürdürülebilir balıkçılık için filonun mevcut doğal kaynaklara uyumunu sağlamayı amaçlamalıdır. Refah seviyesinin yükseltilmesi acısından kıyı bölgelerimizde yoksulluğun azaltılması ve kalkınması için birliğin almış olduğu kararlara uyulması gerekmektedir (Anonim, 1995-1997).

Avlanma filosunun teknik ve fiziksel özellikleri üzerine daha önce yürütülen bazı çalışmalar ise; Tietze ve ark, (2001) yılında değişik ülkelerde yapmış oldukları çalışmalarda avlama teknelerinin ekipmanlarını ve ekonomik analizlerini araştırmışlar Colloca ve ark., (2003) Cilento (İtalya) Bölgesindeki avlama filosu ve av ekipmanları incelemiştir. Tzanatos ve ark., (2005) Yunanistan'daki kıyı balıkçılığı üzerine araştırma yapmıştır. Ünal ve ark., (1998) İzmir ili Foça ilçesi, Çeliker ve ark.,(2006) Karadeniz Bölgesi'nde, Yücel, (2006) Orta Karadeniz'de, Uzmanoğlu ve Soylu (2006) Karasu (Sakarya) Bölgesi, Şahin Özen (2006) Tekirdağ ilindeki 
balıkçı teknelerinin ekipmanları üzerine çalışmışlar yürütmüşlerdir.

$\mathrm{Bu}$ araştırma, Türkiye balıkçılık sektöründe önemli bir paya sahip olan Doğu Karadeniz Bölgesi’ndeki Giresun ilinde avlama filosunun fiziksel ve teknik özellikleri uygulanacak politikalara, yapılacak veya yapılması plânlanan düzenlemelere ve/veya alınacak tedbirlere 1 şık tutacak verilerin elde edilmesi amacıyla planlanmıştır.

\section{MATERYAL ve METOD}

Doğu Karadeniz Bölgesi'nde Giresun ilinde 8 ilçe (Piraziz, Bulancak, Merkez, Gülburnu, Tirebolu, Görele, Çavuşlu, Eynesil) araştırma alanını oluşturmuş olup, Piraziz, Bulancak, Merkez birinci grubu, Gülburnu ve Tirebolu ikinci grubu, Görele, Çavuşlu, Eynesil ilçeleri ise üçüncü grubu oluşturmaktadır (Şekil 1). Bu gruplardaki balıkçı barınaklarına kayıtlı avlama tekneleri araştırma materyalini oluşturmuştur. Anket formları tekne sahipleri ile yüz yüze görüşmeler yoluyla doldurulan anket formlarından elde edilen orijinal veriler yardımıyla toplanmıştır.

Giresun ilinde balıkçılık faaliyetinde bulunan avlama teknelerinin; boy, kullanım şekli, yaş, motor gücü, yapım malzemesi, mülkiyet durumu, satın alınma şekli, kullandıkları avlama ağları ve ekipmanlar ve elektrikli cihaz donanımına ilişkin verileri elde edecek şekilde, (Sabatella, ve Franquesa,2003; Anonim 1997-2004)'de bildirilen konular ile Tarım ve Köy işleri Bakanlığı Koruma ve
Kontrol Genel Müdürlüğü Su Ürünleri Daire Başkanlığı ve Ankara Üniversitesi Su Ürünleri Araştırma ve Uygulama Merkezi'nin (Çeliker vd., 2006) Tarımsal Ekonomi Araştırma Enstitüsü tarafindan yapılan projeleri doğrultusunda hazırlanmıştır.

Giresun ilinden araştırma yapılan bölgede çekilecek örneğin büyüklüğünün tespitinde; tekneler küçükten büyüğe, tekne boyları itibariyle sıralanmış ve yoğunlukları dikkate alınarak; 12 m küçük ve 12 m'den büyük tekne ve grupları olarak sınıflandırılmıştır. Ayrıca tekneler yaptıkları avcılık çeşidine göre de Kıyı balıkçılığı ve Gırgır balıkçılığı olarak ayrılarak incelenmiştir. Tabakalı Tesadüfi Örnekleme Yöntemine göre her gruptan anket yapılacak tekne sayısı belirlenmiştir. Bu amaçla, Giresun İli Balıkçılık ve Su Ürünleri Şube Müdürlüğü'nden avlama ruhsatı almış ve balıkçı barınaklarına kayıtlı olan 630 balıkçı teknesinin ilçelere göre dağılımı belirlenmiştir. Avlama teknesinden çekilecek örnek büyüklüğü Yamane (2001)'nin belirttiği yönteme göre yapılmıştır.

Avlama filosunun teknik yönden irdelenmesinde Yamane (2001) ve Düzgüneş vd., (1983)'in yöntemleri kaynak olarak kullanılmıştır. Karşılaştırma ve kontrollerde önem seviyesi, P: 0,05 olarak kabul edilmiştir. Ayıca, kullanılan anket formları çeşitli araştırmalarda da daha önce kullanılmıştır (Anonim1997-2004).

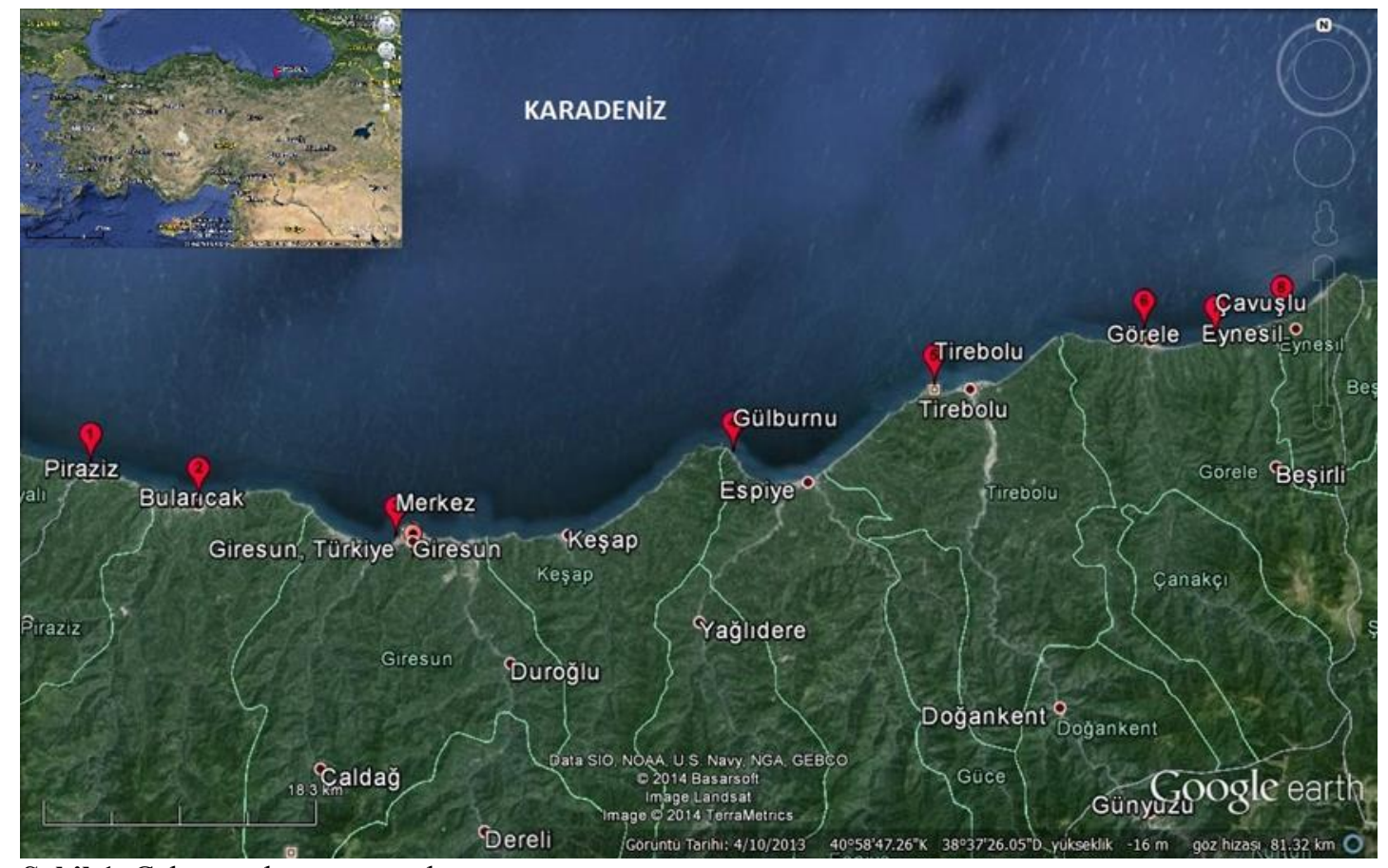

Şekil 1. Çalışma alanının genel görünümü 


\section{BULGULAR}

Araştırmada öncelikli olarak tekneler boy sinıflarına ayrılarak o boy sınıfındaki popülasyon büyüklükleri belirlenmiştir. $\mathrm{Bu}$ verilere göre popülasyon büyüklüğü 630 olarak hesaplanmıştır. Bu verilerden çekilen örnek büyüklüğü ise 167 olarak belirlenmiştir (Tablo1).

Tablo1. Tekne boy gruplarına göre popülasyon büyüklüğü ve hesaplanan örnek büyüklüğü

\begin{tabular}{ccc}
\hline $\begin{array}{c}\text { Tekne Boy } \\
\text { Gurupları (m) }\end{array}$ & $\begin{array}{c}\text { Popülasyon } \\
\text { Büyüklüğ̈̈ (N) }\end{array}$ & $\begin{array}{c}\text { Örnek } \\
\text { Büyüklüğü (n) }\end{array}$ \\
\hline$<8$ & 493 & 111 \\
$8-11,9$ & 109 & 50 \\
$12-29,9$ & 22 & 4 \\
$\geq 30$ & 6 & 2 \\
\hline Toplam & 630 & 167 \\
\hline
\end{tabular}

Balıkçılık aktivitelerinde bulunan avlama tekneleri balıkçılık tipine göre, kıyı balıkçılığı (küçük ölçekli balıkçılık) ve orta/büyük ölçekli balıkçılık olmak üzere iki grupta incelenmiştir. Balıkçılarının \%96'sı kıyı balıkçı teknesi, \% 4'ü ise orta ve büyük ölçekli balıkçı teknesi olarak kullanılmaktadır. Araştırma alanındaki karasularında trol ve trol-girgır yasak olduğundan sadece orta ve büyük tekneler gırgır avcılığı yapmaktadır. Küçük ölçekli balıkçılık yapan teknelerinden örnek olarak seçilenler, genellikle 12 m'den küçük olup, kıyıdan ayrıldıkları bölgede avcılık yapmaktadır. Daha sonra avlarını aynı bölgede karaya bırakmaktadır. Örnek olarak seçilen avlama teknelerinin maksimum $45 \mathrm{~m}$ boyunda olduğu, minimum 3,5 m arasında olduğu belirlenmiştir. Ayrıca kıyı balıkçılığı yapan (küçük ölçekli balıkçılık) teknelerinin boyları ise 3,50 m ile 11,9 m arasında değişim gösterdiği ortalama ise $7,17 \mathrm{~m}$ olduğu belirlenmiştir. Orta ve büyük ölçekli balıkçı tekne boyları ise $12 \mathrm{~m}$ ile $45 \mathrm{~m}$ arasında olduğu ve ortalama $27,41 \mathrm{~m}$ olarak belirlenmiştir (Tablo 2).

Tablo 2. Avlama teknelerinin boy grupları ve balıkçılık tipine göre dağılımı ile minimum ve maksimum boyları.

\begin{tabular}{|c|c|c|c|c|c|}
\hline \multirow[t]{2}{*}{ Boy Grupları (m) } & \multicolumn{2}{|c|}{$\begin{array}{c}\text { Örnek } \\
\text { Seçilen } \\
\text { Avlama } \\
\text { Tekneleri }\end{array}$} & \multirow[t]{2}{*}{ Min } & \multirow[t]{2}{*}{ Mak } & \multirow[t]{2}{*}{ Ort } \\
\hline & $\mathbf{N}$ & $\mathbf{n}$ & & & \\
\hline$<8$ & 493 & 111 & 3,5 & 7,8 & 6,25 \\
\hline $8-11,9$ & 109 & 50 & 8 & 11 & 9,23 \\
\hline $12-29,9$ & 22 & 4 & 12 & 28 & 19,25 \\
\hline$\geq 30$ & 6 & 2 & 42,5 & 45 & 43,75 \\
\hline \multicolumn{6}{|l|}{ Balıkçılık Tipi } \\
\hline $\begin{array}{l}\text { Küçük Ölçekli } \\
\text { Balıkçılık (Kıyı } \\
\text { Balıkç1ığı) Ort. }\end{array}$ & 612 & 161 & 3,5 & 12 & 7,17 \\
\hline $\begin{array}{c}\text { Orta ve Büyük } \\
\text { Ölçekli Balıç̧ıllı } \\
\end{array}$ & 28 & 6 & 12 & 45 & 27,41 \\
\hline Genel Ortalama & 630 & 167 & 3,5 & 45 & 7,90 \\
\hline
\end{tabular}

Avlama teknelerinin yaş dağılımları 0-45 yıl arasında değiştim göstermiş olup ortalama 16,15 yıl olduğu belirlenmiştir (Tablo 4). Araştırmada en yaşlı boy grubunu
8 m'den daha küçük olan tekneler oluştururken (19,92 y1l), en genç grubu ise $12-29,9 \mathrm{~m}$ boy grubunda olanlar oluşturuyor (11,75 y1l). Tekne boy grubu ile ortalama tekne yaşı karşılaştırıldığında aralarında anlamlı bir ilişkinin olmadığı belirlenmiştir $(\mathrm{r}=0,2086)$. Avlama teknelerinin 12 m'den küçük olanlarının en yaşlısının yaşı 45 yıllık, 12 m'den büyük olanlarının en yaşlısının yaşı ise 18 yıl olarak saptanmıştır ( Tablo 3). Avlama teknelerinin yaşları 5'er yıllık aralıklarla yaş gruplarına ayrıldığında, \%23'ünün 1520, \%21'inin 10-15, \%19 'unun 20-25, \%9'unun 5-10, \%4'ünün 30-35, \%3'ünün 40-45, \%2'sinin ise 35-40 yaşlarında olduğu saptanmıştır. Avlama tekneleri arasında en yüksek oran 15-20 yaş grubunda 8 yaşından küçük avlama teknelerinde tespit edilmiştir. $\mathrm{Bu}$ yaş grubunu yine aynı boy grubu üyelerinin 10-15 yaş gurubu takip etmiştir (Şekil 2).

Tablo 3. Avlama teknelerinin yaş dağılımı (\%).

\begin{tabular}{cccc}
\hline Boy Grupları (m) & Minimum & Maksimum & Ortalama \\
\hline$<8$ & 1 & 45 & 16,92 \\
$8-11,9$ & 2 & 35 & 15,34 \\
$12-29,9$ & 2 & 18 & 11,75 \\
$\geq 30$ & 2 & 3 & 2,5 \\
\hline Balıkçılık Tipi & & & \\
\hline $\begin{array}{c}\text { Küçük Ölçekli Balıkçılık } \\
\text { (Kıyı Balıçılığı) }\end{array}$ & 1 & 45 & 16,43 \\
Orta ve Büyük Ölçekli & & & 8,66 \\
Balıçılık & 2 & 35 & 16,23 \\
\hline Genel Ortalama & 1 & 45 &
\end{tabular}

Avlama teknelerinden 8 yaşından küçük ve 10-15 yaş arasındaki avlama tekneleri sayısı en fazla yığılma olan grubu oluşturduğu gibi bu grubu yine aynı boy grubundan 20-25 yaş grubu takip etmiştir. Balıkçılık faaliyetinde bulunan avlama teknelerinin \%20'sinin yaşı, 10'dan küçüktür. $\mathrm{Bu}$ gruptaki avlama teknelerinin yarısından fazlasının (\%64'ünün) yaşı 20 den küçük, \%36'sının yaşı ise 20'den büyüktür.

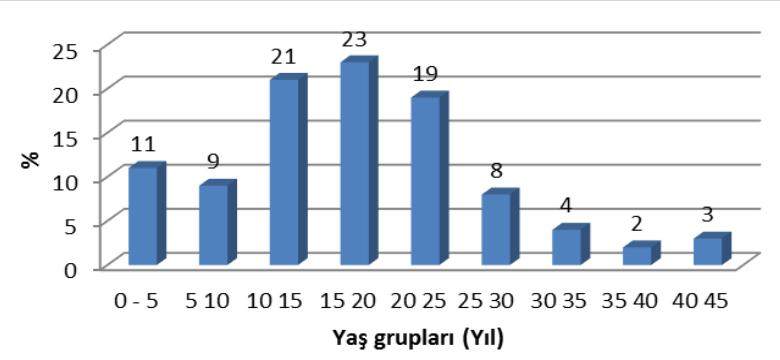

Şekil 2. Avlama teknelerinin yaş gruplarına göre dağılımı (\%).

Kıyı balıkçılığı yapan teknelerinin \% 26’sinin yaşı 20'den küçüktür. $\mathrm{Bu}$ gruptaki avlama teknelerinin yarısından fazlasının (\%60'ının) yaşı 20 den küçük, \%30'unun yaşı ise 20'den büyüktür (Şekil 3).

Orta ve büyük ölçekli balıkçılık faaliyetinde bulunan avlama teknelerinden yarısı 5 yaşın altındadır. En yaşlı grup 15-20 yaş grubudur. Orta ve büyük ölçekli 
balıkçılık yapan teknelerin ise \% 67'isi 15 yaşından küçüktür (Şekil 4).

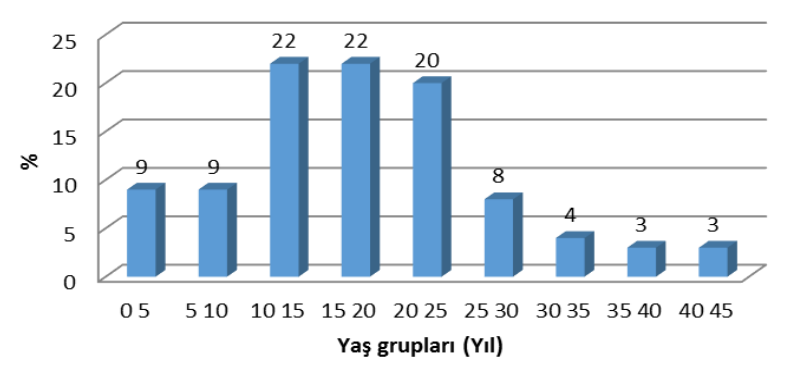

Şekil 3. Kıyı balıkçılığı yapan avlama teknelerinin yaş gruplarına göre dağılımı (\%).

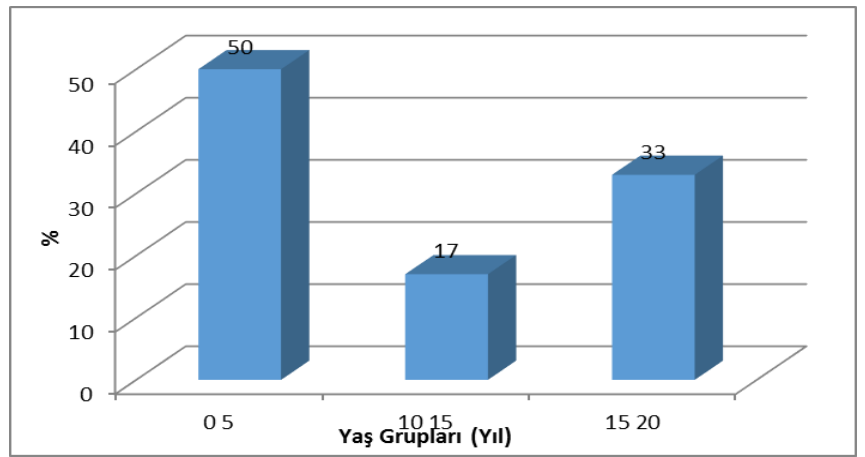

Şekil 4. Orta ve büyük ölçekli avlama teknelerinin yaş gruplarına göre dağılımı (\%).

Yapım malzemesi olarak avlama teknelerinin \% 98'inin ahşaptan, \%2'sinin ise saçtan imal edildiği tespit edilmiştir. 12 m'den küçük teknelerin tamamı ahşap, 28 m'den büyük teknelerin tamamı ise saç malzemeden imâl edilmiştir. 12-29,9 m boy grubundaki teknelerin \%66,6's1 ahşap, \%33,3'ü ise saçdan imal edilmiştir. $30 \mathrm{~m}$ 'den daha büyük boylardaki teknelerin tamamı saç malzemeden yapılmıştır. Küçük ölçekli balıkçılık yapan teknelerin tamamı (\%100) ahşaptan imâl edilmiştir. Orta ve büyük ölçekli balıkçılık yapan avlama teknelerinin \% 50'si ahşap, diğer yarısı da (\%50'si), saç malzemeden yapılmıştır (Tablo 4).

Tablo 4. Avlama teknelerinin yapım malzemesi.

\begin{tabular}{llll}
\hline Boy Grupları (m) & Minimum & Maksimum & Ortalama \\
\cline { 2 - 3 } & Ahşap & Saç & \\
\hline$<8$ & 111 & - & 111 \\
$8-11,9$ & 50 & - & 50 \\
$12-29,9$ & 3 & 1 & 4 \\
$\geq 30$ & - & 2 & 2,5 \\
\hline
\end{tabular}

\begin{tabular}{llll}
\hline Balıkçılık Tipi & & & \\
\hline Küçük Ölçekli & & & \\
Balıçıılık $\quad$ Kıy1 & 161 & & \\
Balıçılığı) & Toplam \\
Orta ve Büyük & & & \\
Ölçekli Balıkçılık & 3 & 3 & 6 \\
\hline Genel Ortalama & 164 & 3 & 167 \\
\hline
\end{tabular}

Yapım malzemesi olarak avlama teknelerinin \% 98'inin ahşaptan, \%2'sinin ise saçtan imal edildiği tespit edilmiştir. 12 m'den küçük teknelerin tamamı ahşap, 28 m'den büyük teknelerin tamamı ise saç malzemeden imâl edilmiştir. 12-29,9 m boy grubundaki teknelerin \%66,6's1 ahşap, \%33,3'ü ise saçdan imal edilmiştir. $30 \mathrm{~m}$ 'den daha büyük boylardaki teknelerin tamamı saç malzemeden yapılmıştır. Küçük ölçekli balıkçılık yapan teknelerin tamamı (\%100) ahşaptan imâl edilmiştir. Orta ve büyük ölçekli balıkçılık yapan avlama teknelerinin \% 50'si ahşap, diğer yarısı da (\%50'si), saç malzemeden yapılmıştır (Tablo 4).

Avlama teknelerinin $\quad \% 76,2$ 'sinin mülkiyeti kendine ait teknelerden oluşmaktadır. Ortak tekne sahiplerinin \%20,92 aile içi ve \%1,92 aile dış1 ortaklıklardan oluşmaktadır. Giresun balıkçılarının avlanma teknelerini kiralama $(\% 1)$ yoluna gitmemeleri çok dikkat çekici bir sonuçtur (Tablo 5). Tekne boyu 8 metreden küçük olan avlama teknelerinin mülkiyetleri en fazla $(\% 53,2)$ tek tekne sahiplerine aittir. 8 metreden küçük tekne sahiplerinin ortaklık kurarken aile içindeki $(\% 10,71)$ ortaklıkları tercih ettikleri tespit edilmiştir. Kiralama yoluyla avcılık yapan avlama teknelerine baktığımızda yine 8 metreden küçük avlama teknelerinden sadece bir üyesinin kiralamayı tercih ettiğini görmekteyiz. Tekne boyu 8-12 metre boy grubunda $\% 21,28$ 'i teknenin mülkiyeti tek kişiye ait iken \%7,77'lik oran ile de tekne sahipleri mülkiyette aile içi ortaklığı tercih etmişlerdir ancak çok küçük oranla( $\% 0,5)$ aile dişı ortaklık tespit edilmiştir. 12-30 metre boyundaki tekne sahiplerinin $\% 1,52$ 'si teknenin mülkiyeti tek kişiye ait iken \%1,26'lık oran ile de tekne sahipleri mülkiyette aile içi ortaklığı tercih etmişlerdir.

$\mathrm{Bu}$ grubun üyeleri tekne mülkiyeti için aile dış1 ortaklığı ve kiralamayı tercih etmemişlerdir. 30 metreden büyük avlama tekne sahipleri tekne mülkiyeti için tek kendilerine ait tekne sahibi olmayıp aile içi ortaklık yoluyla $(\%$ 1,26) tekne mülkiyeti sahipleri olmuşlardır. Tüm boy gruplarından 30 metreden büyük tekneler hariç en az $\% 50$ 'sinin tekne mülkiyeti kendilerine aittir. 8 metreden küçük tekne grubunun \% 80'ninin tekne mülkiyeti kendisine aittir. Tekne boyu arttıkça mülkiyette kiralama yolu tercih edilmemiştir ve ortakların aile içi bireylerden tercih edilme oranı da artmıştır. 8 metreden küçük teknelerde \%16 olan aile içi bireylerle ortaklık, 12 m'den büyük teknelerde \%50'ye ve 30 metreden büyük teknelerde ise \%100 'e ulaşmaktadır.

Balıkçıların \%90‘'ının, balıkçılık faaliyetlerini tek avlama teknesi, \%10'unun ise iki veya daha fazla avlama teknesi ile avcılık yürüttüğü saptanmıştır (Şekil 5). Avlama teknelerinin satın alma şekli, tekne sahibi balıkçıların \%55'inin kendi imkânları, \%19'ünün kredi, \%7'sinin miras ve \%19'u şahıstan borç alarak tekne sahibi oldukları saptanmıştır. Büyük boya sahip teknelerde kredi kullanımının artması beklenirken küçük kıyı balıkçılığı yapan teknelerde kredi kullanımı \%17,9 olarak bulunmuştur. 30 metreden büyük teknelerin $\% 50$ kendisinin $\% 50$ de miras yoluyla sahip olunduğu bulunmuştur (Şekil 6). 
Balıkçılık tipine göre bakıldığında en yüksek oranda kredi kullanan balıkçılar kıyı balıkçılarıdır $(\% 18,24)$, en az oranda kredi kullanan balıkçılar ise gırgır yapan tekne sahipleridir (\%8,70). Kıyı balıkçılarının \%14,24'ü şahıstan borç alma yoluyla tekne sahibi olmuşlardır. Orta ve büyük ölçekli balıkçılardan \% 0,68'i şahıstan borç alarak tekne sahibi olmuşlardır (Şekil 7).

Tablo 5. Boy grupları ve balıkçılık tipine göre asıl avlama teknelerinin mülkiyet dağılımı (\%)

\begin{tabular}{|c|c|c|c|c|c|}
\hline \multirow[t]{4}{*}{ Boy Grupları (m) } & \multicolumn{3}{|c|}{ Tekne Mülkiyeti } & \multirow{4}{*}{ Kira } & \multirow{4}{*}{ TOPLAM } \\
\hline & \multirow[t]{3}{*}{ Kendisinin } & \multicolumn{2}{|c|}{ Ortak } & & \\
\hline & & Aile İçi & Aile & & \\
\hline & & & Dışı & & \\
\hline$<8$ & 53,2 & 10,71 & 1,5 & 1 & 66,41 \\
\hline $8-11,9$ & 21,28 & 7,77 & 0,5 & 0 & 29,55 \\
\hline $12-29,9$ & 1,52 & 1,26 & 0 & 0 & 2,78 \\
\hline$\geq 30$ & 0 & 1,26 & 0 & 0 & 1,26 \\
\hline \multicolumn{6}{|l|}{ Balıkçılık Tipi } \\
\hline Küçük $\quad$ Ölçekli & & & & & \\
\hline Balıkçılık $\quad$ (Kıyı & 74,88 & 18,24 & 1,92 & 0,96 & 96 \\
\hline \multicolumn{6}{|l|}{ Balıkçılığı) Toplam } \\
\hline Orta ve Büyük & 13 & 268 & 0 & 0 & 4 \\
\hline Ölçekli Balıkçılık & 1,3 & 2,08 & & & \\
\hline Genel Toplam & 76,2 & 20,92 & 1,92 & 0,96 & 100 \\
\hline
\end{tabular}

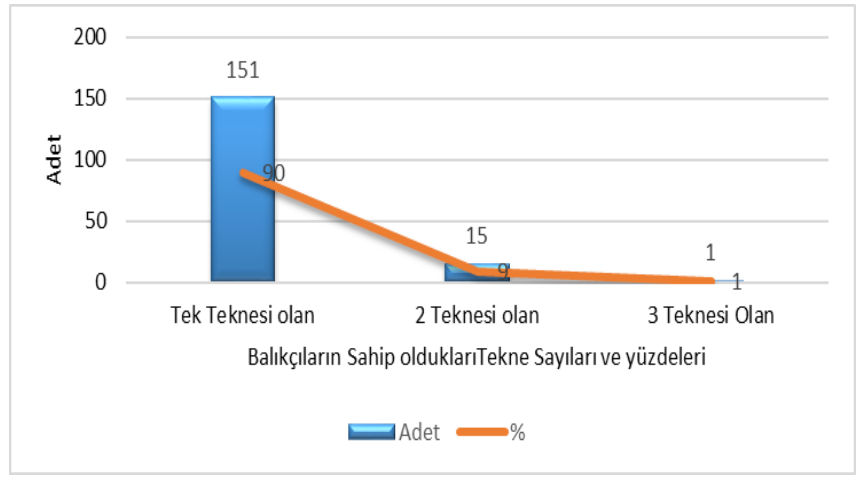

Şekil 5. Balıkçıların genel olarak sahip oldukları tekne sayıları.

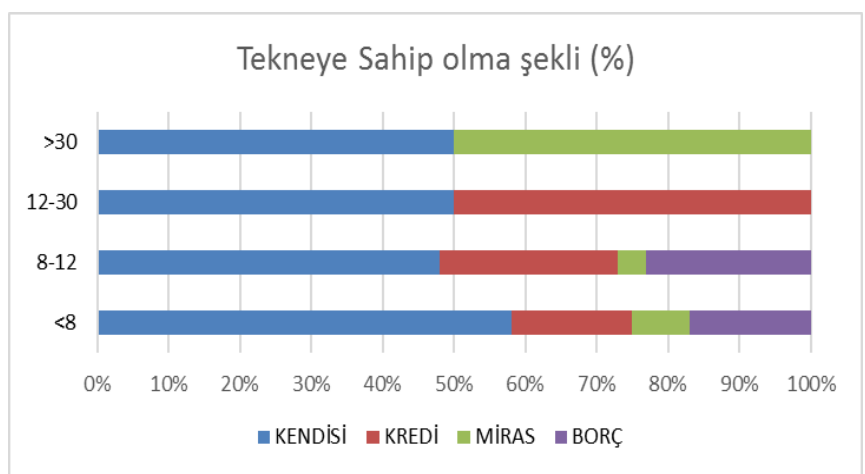

Şekil 6. Tüm avlama teknelerinin satın alınma şekli (\%).

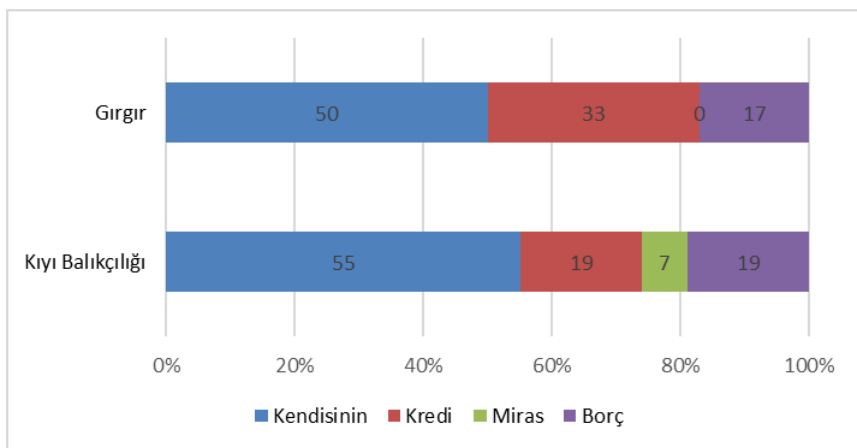

Şekil 7. Balıkçılık tipine göre avlama teknelerinin satın alınma şekli (\%).

Avlama teknelerindeki ağlar ve diğer avlama araçları; ağlardan sade ağlar, fanyalı ağlar, gırgır ağlar, tekneye bağlı kaldırma ağlarını kullandıkları gibi dip trolü, çift gemili orta su trolü, dreç, algarna, çapari, parakete, el oltası ve sabit oltalar (el ile kullanılan) gibi farklı özelliklerdeki oltalar ve dalış takımlarına da rastlanmıştır.

Algarna, dreç ve dalış takımları, avcılığında sadece bu av araç-gereçlerinin kullanıldığı belirli su ürünlerinin avcılığını yapan kıyı balıkçılarda tespit edilmiştir. Ağların donatımı, kullanımı ve adlandırılmasında bazı farklılıklar olsa da, balıkçıların benzer ağ çeşitlerini kullandıkları saptanmıştır.

Kıyı balıkçılığı yapan avlama teknelerinin \%46'sında olta bulunması nedeniyle, kıyı balıkçılarında olta ve ağlar hemen hemen birlikte yaygın bir av aracı olarak 
tespit edilmiştir. Giresun ilinde balıkçılık yapan avlama teknelerinde, olta dışında çoğunluğunu ağların oluşturduğu, 23 avlama aracı kullanıldığı belirlenmiştir bunlar; genellikle mezgit uzatması (\%86), barbunya ağı (\%76), palamut uzatması(\%63), saçma ağı (\%62), kalkan ağı (\%39) ve algarna (\%32) oranlarında bulunmaktadır (Tablo 6).

Kıyı balıkçılığı yapan avlama teknelerinde çoğunlukla mezgit-palamut uzatmaları veya mezgitpalamut-barbunya uzatmaları ile saçma kombinasyonlarının bulunduğu, endüstriyel balıkçılık yapan avlama teknelerinde gırgır ağları, dip trolü, çift gemi ve orta su trolü bulunmaktadır.

Gırgırlarda tekne boyu büyüdükçe avlama araçlarının sadeleştiği, hamsi-istavrit veya hamsi-palamut gırgırı kombinasyonlarının ağırlık kazandığı gözlenmiştir. Trol-gırgır teknelerinde orta su trolü, yerini palamut gırgırı ve palamut uzatmaları yer almıştır. Orta ve büyük ölçekli balıkçılıkta, hamsi, barbun, mezgit gırgırının yanında orta ve dipsu trolü çeşitlerinin az da olsa temsil edildiği bir gruptur.

Tablo 6. Giresun ili balıkçılık yapan teknelerde bulunan avlama araç-gereçleri $(\%)$

\begin{tabular}{llll}
\hline Avlama Aracı* & \% n & Avlama Aracı & $\%$ n \\
\hline Mezgit Uzatması & 86 & Tirsi Uzatması & 17 \\
Barbunya Uzatması & 76 & Rus Kefali Volisi & 16 \\
Palamut Uzatması & 63 & Lüfer Uzatması & 15 \\
Saçma & 62 & Alamana & 8 \\
Kalkan Uzatması & 39 & Dalgıc Takımı & 7 \\
Algarna & 32 & Iğrıp & 4 \\
İstavrit Volisi & 31 & Zıpkın & 4 \\
Yerli Kefal Uzatması & 26 & Dreç & 3 \\
İskorpit Uzatması & 23 & Dip Trolü & 3 \\
Zargana Uzatması & 21 & Orta Su Trolü & 2 \\
Çinekop Uzatması & 20 & Çapari & 2 \\
İstavrit Uzatması & 20 & & \\
\hline
\end{tabular}

* Oltalar dâhil edilmemiştir.

$\mathrm{Bu}$ araştırmada Tablo 7 de belirtilen tüm av araçlarından hepsi en az \%50 oranında tüm teknelerde bulunduğu tespit edilmiştir.

Tablo 7. Gırgır teknelerinde bulunan avlama araçları (\%).

\begin{tabular}{llll}
\hline Avlama Aracı* $^{*}$ & $\% \mathrm{n}$ & Avlama Aracı & $\% \mathrm{n}$ \\
\hline Mezgit Uzatması & 83 & Tirsi Uzatması & 50 \\
Barbunya Uzatması & 100 & Rus Kefali Volisi & 67 \\
Palamut Uzatması & 67 & Lüfer Uzatması & 67 \\
Saçma & 83 & Alamana & 50 \\
Kalkan Uzatması & 83 & Dalgıç Takımı & 50 \\
Algarna & 83 & Iğrıp & 50 \\
İstavrit Volisi & 67 & Zıpkın & 50 \\
Yerli Kefal Uzatması & 83 & Dreç & 50 \\
İskorpit Uzatması & 67 & Dip Trolü & 50 \\
Zargana Uzatması & 50 & Orta Su Trolü & 50 \\
Çinekop Uzatması & 83 & Çapari & 50 \\
İstavrit Uzatması & 50 & & \\
\hline
\end{tabular}

* Oltalar dâhil edilmemiştir.
Avlama teknelerinde telsizden akıntı ölçer kadar çok çeşitli elektrikli cihaz ve ekipmanın bulunduğu saptanmıştır (Tablo 7) 8 metreden küçük avlanma teknelerinin telefon (\%20), telsiz(\%6), SSB telsiz(\%2), radar(\%18),iskandil(\%9) ve akıntı ölçer (\%1) oranında sahip oldukları teknolojik donanım olarak tespit edilmiştir. Avlanma teknelerinin boyu arttıkça sahip oldukları teknolojik donanımda artmıştır hatta 30 metreden daha büyük avlama teknelerinin hepsinde tüm donanımlar (\%100) bulunmaktadır (Tablo 8).

Tablo 8. Boy grupları ve balıkçılık tipine göre avlama teknelerinde bulunan elektrikli cihaz ve ekipmanlar (\%n)

\begin{tabular}{|c|c|c|c|c|c|c|}
\hline \multirow{2}{*}{$\begin{array}{l}\text { Elektrikli } \\
\text { Cihazlar }\end{array}$} & \multicolumn{4}{|c|}{$\begin{array}{c}\text { Boy Grupları Elektrikli } \\
\text { Cihazlar (m) }\end{array}$} & \multicolumn{2}{|c|}{ Balıkçılık Tipi (\%n) } \\
\hline & $<8$ & $\begin{array}{c}8- \\
11,9\end{array}$ & $\begin{array}{c}12- \\
29,9\end{array}$ & $>\mathbf{3 0}$ & $\begin{array}{c}\text { Kıyı } \\
\text { Balıkçılığı }\end{array}$ & Girgır \\
\hline Telsiz & 6 & 32 & 75 & 100 & 14 & 83 \\
\hline Telefon & 20 & 18 & 50 & 100 & 81 & 67 \\
\hline SSB Telsiz & 2 & 4 & 50 & 100 & 2 & 67 \\
\hline Sonar & - & - & 50 & 100 & - & 67 \\
\hline Radar & 18 & 42 & 75 & 100 & 25 & 83 \\
\hline Jeneratör & - & 4 & 50 & 100 & 1 & 67 \\
\hline İskandil & 9 & 36 & 50 & 100 & 17 & 67 \\
\hline GPS- Uydu & - & 2 & 50 & 100 & 1 & 67 \\
\hline Fishpomp & - & - & 25 & 100 & - & 50 \\
\hline Faks & - & - & 50 & 100 & - & 67 \\
\hline EcoSaunder & - & 2 & 50 & 100 & 1 & 67 \\
\hline Buz Makinası & - & - & 50 & 100 & - & 67 \\
\hline Oto pilot & - & - & 50 & 100 & - & 67 \\
\hline Akıntıölçer & 1 & - & 50 & 100 & 1 & 67 \\
\hline
\end{tabular}

Kıyı balıkçılığı yapan avlama teknelerinde daha çok avın yerini bulmaya yarayan sonar ve eco-saunder VHF telsiz magnetik pusula, telefon ve akıntı ölçer dışında elektronik cihaza rastlanmamıştır. Orta ve büyük avlama teknelerinde; bu çalışmamızda sadece gırgır tekneleri ile çalıştığımız için gırgır teknelerinde avın bulunmasına yarayan tüm ekipman (Sonar, Echo-Sounder, akıntı Ölçer, VHF Telsiz [Adet], SSB telsiz, kuş radarı, kumpas radar, ağ radarı, harita cihazı (GPS), manyetik pusula olduğu gibi taşıma teknesine almaya yarayan fishpomp ve avın bozulmasını önlemek için buz makinesi ve jeneratör gibi ekipmanlar da mevcuttur. Endüstriyel balıkçılık yapan büyük boy teknelerde belirtilen tüm elektronik cihazlar mevcuttur.

Avlama teknelerinin motor güçlerinin 7-1250 BG arasında değiştiği belirlenmiştir. 8 metreden daha küçük avlama tekneleri ortalama 19,33 BG ile en küçük motor gücüne sahip grubu oluşturmaktadır. En büyük motor gücü tekne boy büyüklüğü ile doğru orantılı olup 30 metreden daha büyük tekne grubunda ortalama 1000BG ile en büyük motor güçlerine sahip grubu oluşturmaktadır. II. ve III. motor destekleri 10 metre av teknelerinden daha büyük teknelerde bulunmaktadır. II.motor gücü 8-12 metre grubu üyelerinden 10 av teknesinin ortalaması 25,3 BG, 12-30 metre boy grubunda iki av teknesinin ortalamasi 725 BG'dür. III.motor desteği 30 metreden daha büyük iki av teknesinde ortalama 875 BG kuvvetindee motor kullanıldığ tespit edilmiştir (Tablo 9). Kıyı balıkçılığı yapan avlama tekneleri, en küçük motor gücüne ortalama 36,24 BG ile 
sahip grubu oluşturmaktadır. Orta ve Büyük Ölçekli Balıkçılığı oluşturan gırgır teknelerinde birinci motorların ortalama gücü 612,5 BG’dür (Tablo 9).

Kıyı balıkçılıklarında II.motor takviyesini grup üyelerinden 10 av teknesinde ortalama 25,3 BG'lik motor gücüyle tespit edilmiştir. Kıyı balıkçılarında III.motor kullanmamışlardır. Orta ve büyük balıkçılarda II. motor desteği motor gücü ortalamas1 737,5 BG'de ve III. motor desteği 30 metreden daha büyük iki av teknesinde ortalama 875 BG kuvvetinde kullanıldığı tespit edilmiştir.

Tablo 9. Boy grupları ve balıkçılık tipine göre avlama teknelerinin motor güçleri (BG)

\begin{tabular}{|c|c|c|c|c|c|}
\hline \multirow{3}{*}{ Boy Grupları (m) } & \multicolumn{5}{|c|}{ Motor Gücü (BG) } \\
\hline & \multicolumn{3}{|c|}{ I. Motor } & \multirow{2}{*}{$\begin{array}{c}\begin{array}{c}\text { II. } \\
\text { Motor }\end{array} \\
\text { (ort.) } \\
\end{array}$} & \multirow{2}{*}{$\begin{array}{c}\begin{array}{c}\text { III. } \\
\text { Motor }\end{array} \\
\text { (ort.) }\end{array}$} \\
\hline & Min. & Max. & Ort. & & \\
\hline$<8$ & 7 & 85 & 19,33 & - & - \\
\hline $8-11,9$ & 16 & 168 & 73,78 & $25,3(10)$ & - \\
\hline $12-29,9$ & 65 & 1000 & 418,75 & $725(2)$ & - \\
\hline$\geq 30$ & 750 & 1250 & 1000 & $750(2)$ & $875(2)$ \\
\hline \multicolumn{6}{|l|}{ Balıkçılık Tipi } \\
\hline $\begin{array}{c}\text { Küçük Ölçekli } \\
\text { Balıkçılık (Kıyı } \\
\text { Balıç̧ılığ1) Toplam }\end{array}$ & 7 & 168 & 36,24 & 25,3 & - \\
\hline $\begin{array}{l}\text { Orta ve Büyük } \\
\text { Ölçekli } \\
\text { Balıç̧ılık }\end{array}$ & 65 & 1250 & 612,5 & 737,5 & 875 \\
\hline
\end{tabular}

\section{TARTIŞMA ve SONUÇ}

Giresun ili balıkçılarının \%96'sı kıyı balıkçı teknesi, \% 4'ü ise orta ve büyük ölçekli balıkçı teknesi olarak kullanılmaktadır. Giresun ili karasularında trol ve trol-gırgır yasak olduğundan sularımızda sadece orta ve büyük tekneler olarak gırgır avcılığı yapılmaktadır. İldeki ruhsatlı teknelerin boyları incelendiğinde; 8 metreden küçük tekne grubunun minimum 3,5 metre, maksimum 6,25 metre olduğu, 30 metreden büyük boy grubundaki tekne grubunda ise grubunun minimum $42,5 \mathrm{~m}$ ve maksimum 45 metre boyundaki tekneler ile avcılık yaptığı tespit edilmiştir.

Avlama teknelerinin yaşlarının 0-45 yıl arasında değiştiği ve ortalama 16,15 yıl olduğu saptanmıştır. 8 m'den daha küçük boy grubundaki avlama tekneleri ortalama 16,92 yıl ile en yaşlı, 30 metreden daha büyük tekneler en genç avlama teknelerini oluşturmaktadır. Tekne boy grubu ile ortalama tekne yaşı arasında anlamlı ilişki bulunamamıştır $(r=0,2086)$.

Küçük ölçekli balıkçı tekneleri (16,43 yıl), orta ve büyük ölçekli balıkçılık yapan avlama teknelerine göre ortalama 7,77 yıl daha eskidir. Avlama teknelerinin 12 m'den küçük olanlarının en yaşlısının yaşı 45 yıllık, 12 m'den büyük olanlarının en yaşlısının yaşı ise 18 yıl olarak saptanmıştır.
Avlama teknelerinin su aldıklarında kolay batmamaları, kıyıya kolayca çıkartılabilmeleri ve tamiratlarının balıkçılar tarafından da yapılabilmesi nedeniyle \% 98'inin ahşaptan, \%2'sinin ise saçtan imal edildiği belirlenmiştir. 12 m'den küçük teknelerin tamamı ahşap, 28 m'den büyük teknelerin tamamı ise saç malzemeden imal edilmiştir. 12-30 $\mathrm{m}$ boy grubundaki teknelerin \%66,6'1 ahşap, \%33,3'ü ise saçtan imal edilmiştir. 30 m'den daha büyük boylardaki teknelerin tamamı saç malzemeden yapılmıştır. Kıyı balıkçılığı faaliyetinde bulunan avlama teknelerinin tamamı (\%100) ahşaptan imal edilmiştir. Orta ve büyük ölçekli balıkçılık yapan avlama teknelerinin \% 50'si ahşap, diğer yarısı da (\%50’si), saç malzemeden yapılmıştır.

Balıkçıların teknelerinin \%76'sının mülkiyeti kendine, \%23'ü ise mülkiyeti ortak tekneler ile balıkçıllk faaliyetinde bulundukları tespit edilmiştir. Avlanma teknelerini kiralama $(\% 1)$ yoluna gitmemeleri çok dikkat çekici bir sonuçtur. Tüm boy gruplarından 30 metreden büyük tekneler hariç en az \%50'sinin tekne mülkiyeti kendilerine aittir. 8 metreden küçük tekne grubunun \% 80 'ninin tekne mülkiyeti kendisine aittir. Tekne boyu arttıkça mülkiyette kiralama yolu tercih edilmemiştir ve ortakların aile içi bireylerden tercih edilme oranı da artmıştır. 8 metreden küçük teknelerde $\% 16$ olan aile içi bireylerle ortaklık, 12 m'den büyük teknelerde $\% 50$ 'ye ve 30 metreden büyük teknelerde ise $\% 100$ 'e ulaşmaktadır. Kıyı balıkçılığında teknelerin mülkiyetlerinin \%78'i, gırgırların \%33'ü balıkçıların kendilerine aittir. Tekne boyuyla birlikte tekne ve av donanımı sermayesi arttığından, gırgır mülkiyetinde ortak olanların oranı kıyı balıkçılarından çok daha yüksek olup ortaklığın sadece aile bireyleri arasında gerçekleştiği tespit edilmiştir.

Kıyı balıkçılığı yapan balıkçıların sadece \%7'sinin ikinci avlama teknesi veya taşıma teknesi bulunmaktadır. Üçüncü teknesi bulunan sadece bir balıkçı tespit edilmiştir. Giresun ili balıçılık faaliyetinde bulunan avlama teknesi sahibi balıkçıların \%55'inin kendi imkânları, \%19'ünün kredi, \%7'sinin miras ve \%19'u şahıstan borç alarak tekne sahibi oldukları saptanmıştır.

Tekne boyu büyüdükçe şahıstan borç alma yoluyla tekne sahibi olanların oranı düşmüştür, 12-45 $\mathrm{m}$ boy dağılımında itibaren şahıstan borç alarak tekne sahibi olan balıkçı bulunmamaktadır. Büyük boya sahip teknelerde kredi kullanımının artması beklenirken küçük kıyı balıkçılığı yapan teknelerde kredi kullanımı \%17,9 olarak bulunmuştur. 30 metreden büyük teknelerin $\% 50$ kendisinin $\% 50$ de miras yoluyla sahip olunduğu bulunmuştur. Balıkçılık tipine göre bakıldığında en yüksek oranda kredi kullanan balıkçılar kıyı balıkçılarıdır $(\% 18,24)$, en az oranda kredi kullanan balıkçılar ise gırgır yapan tekne sahipleridir $(\% 8,70)$ bunun sebebinin tüm büyük tekne sahiplerine ulaşılamamış olunması olabilir. Kıyı balıkçılarının \%14,24’ü şahıstan borç 
alma yoluyla tekne sahibi olmuşlardır. Orta ve büyük ölçekli balıkçılardan \% 0,68'i şahıstan borç alarak tekne sahibi olmuşlardır.

Giresun İl'inde kayıtlı ve limanlarında bulunan teknelerde balıkçılığın temel avlama aracı ağlardır. Kıyı balıkçılı̆̆ı yapan avlama teknelerinin \%46'sında olta bulunması nedeniyle, kıyı balıkçılarında olta ve ağlar hemen hemen birlikte yaygın bir av aracı olarak tespit edilmiştir. Giresun ilinde balıkçılık yapan avlama teknelerinde, olta dışında çoğunluğunu ağların oluşturduğu, 23 avlama aracı kullanıldığı belirlenmiştir bunlar; genellikle mezgit uzatması (\%86), barbunya ağı (\%76), palamut uzatması(\%63), saçma ağı (\%62), kalkan ağı $(\% 39)$ ve algarna (\%32) oranlarında bulunmaktadir.

Gırgırlarda tekne boyu büyüdükçe avlama araçlarının sadeleştiği, hamsi-istavrit veya hamsi-palamut gırgırı kombinasyonlarının ağırlık kazandığı gözlenmiştir.

Orta ve büyük ölçekli balıkçılıkta, hamsi, barbun, mezgit gırgırının yanında endüstriyel balıkçılığın yapıldığı teknelerde orta ve dipsu trolü çeşitlerinin az da olsa temsil edildiği tespit edilmiştir. Giresun ili'ndeki avlama teknelerinde telsizden akıntıölçer kadar çok çeşitli elektrikli cihaz ve ekipmanın bulunduğu saptanmıştır. 8 metreden küçük avlanma teknelerinin telefon (\%20), telsiz( $\% 6)$, SSB telsiz(\%2), radar(\%18),iskandil(\%9) ve akıntı ölçer (\%1) oranında sahip oldukları teknolojik donanım olarak tespit edilmiştir. Avlanma teknelerinin boyu arttıç̧a sahip oldukları teknolojik donanımda artmıştır hatta 30 metreden daha büyük avlama teknelerinin hepsinde tüm donanımlar bulunmaktadır.

Kıyı balıkçılığı yapan avlama teknelerinde daha çok avın yerini bulmaya yarayan sonar ve eco-saunder, VHF telsiz, magnetik pusula, telefon ve akıntıölçer dışında elektronik cihaza rastlanmamıştır. Orta ve büyük avlama teknelerinde; bu çalışmamızda sadece gırgır tekneleri ile çalıştığımız için gırgır teknelerinde avın bulunmasına yarayan tüm ekipman (Sonar, Echo-Sounder, akıntı Ölçer, VHF Telsiz [Adet], SSB telsiz, kuş radarı, kumpas radar, ağ radarı, harita cihazı (GPS), manyetik pusula olduğu gibi taşıma teknesine almaya yarayan fishpomp ve avın bozulmasını önlemek için buz makinesi ve jeneratör gibi ekipmanlar da mevcuttur. Endüstriyel balıkçılık yapan büyük boy teknelerde belirtilen tüm elektronik cihazlar mevcuttur.

Avlama teknelerinin motor güçlerinin 7-1250 BG arasında değiştiği saptanmıştır. 30 metreden daha büyük tekne grubunda ortalama 1000BG ile en büyük motor güçlerine sahip grubu oluşturmaktadır. II. ve III. motor destekleri 10 metre av teknelerinden daha büyük teknelerde bulunmaktadır. Kıyı balıkçılıklarında II.motor takviyesini grup üyelerinden 10 av teknesinde ortalama 25,3 BG'lik motor gücüyle tespit edilmiştir. Kıyı balıkçılarında III.motor ihtiyaç duymamışlardır. Ancak gırgır tekneleri teknolojik gelişmelere bağlı olarak av sahasına hızlı bir şekilde ulaşmak ve fazla miktarda av elde etmek amaciyla 2. ve 3 . motorların takıldığ 1 , yeni teknelerde ise daha büyük motorlar kullanıldığı saptanmıştır.

\section{ÖNERÍLER}

Doğu Karadeniz Bölgesi balıkçılık filoları bakımından Türkiye balıkçılık sektöründe büyük önem taşımaktadır. Bölge halkının istihdamında çok önemli bir yeri vardır. Bu bölgedeki balıkçılık sektörünün avcılık faaliyetinin gelecek nesillere kalmasını sağlamak yani sürdürülebilir ve verimli olabilmesini sağlamak için aşağıdaki sorunlarının çözümlenmesi gerektiği tespit edilmiştir.

Balıkçılıktan sorumlu resmi otoritelerin tek çatı altında toplanmaması ve yönetimde birçok bakanlık ile birlikte çalışılması ve farklı yönetmeliklere tabi olunması bir çok kamu ve sivil toplum örgütlerinin çalışmalarını aksatmaktadır.

Mevcut balıkçı filolarımızın teknik donanım olarak iyi durumda olması ancak balık stoklarımızın olmaması su ürünleri istihsalinde bir açmazımızdır. Bu sorunu çözmek ancak balıkçılıkla ilgili sivil toplum örgütlerinin yani su ürünleri balıkçı kooperatiflerinin gelişmesi, üyelerinin akademik ve teknik olarak balık stoklarının yönetimi ve korunmaları konusunda eğitilmeleri ve araştırma geliştirme kuruluşları olan enstitü ve üniversitelerin bu konuda ellerini taşın altına koymaları ve karar vericilerinde bunlara kulak vermeleriyle olacaktır.

\section{Teşekkür}

$\mathrm{Bu}$ çalışma Giresun Üniv., Fen Bilimleri Enst. Biyoloji Anabilimdalı altında yürütülmüş “Giresun'da Deniz Balıkçılığı ve Balıkçıların Sosyo-Ekonomik Yapısı” başlıklı Yüksek Lisans Tez çalışmasının bir kısmından üretilmiştir.

\section{KAYNAKLAR}

Anonim. (1995-1997). $\mathrm{Su}$ ürünleri istatistikleri. T.C. Başbakanlık Devlet, İstatistik Enstitüsü, Ankara.

Anonim. (2003-2004). $\mathrm{Su}$ ürünleri istatistikleri. T.C. Başbakanlık Devlet, İstatistik Enstitüsü, Ankara.

Colloca, F., Cirespi, V., Cerasi, S. \& Coppola, S.R. (2003). Evolution Of The Artisanal Fishery Ġn Cilento, Italy: Case Study. FAO, COPEMED, 60 p.

Çeliker, S.A. Ahmet, Dönmez, D., Gül, U., Demir, A., Genç, Y., Kalanlar, Ş., Özdemir, İ. (2006). Karadeniz bölgesi'nde su ürünleri avcılığı yapan 
işletmelerin sosyo-ekonomik analizi. Ankara Üniversitesi Su Ürünleri Araştırma ve Uygulama Merkezi, Tarımsal Ekonomi Araştırma Enstitüsü .1-134.

Düzgüneş, O., Kesici, T. \& Gürbüz, F. (1983). İstatistik metodlar1-I. Ankara Üniversitesi Ziraat Fakültesi Yayın No: 861, Ders Kitabı No: 229, 218 s.

http://www.gumrukkontrolor.org.tr/Yayinlar/Dergiler/50/ 9.html (Erişim tarihi: 23.08.2008).

Mastracchio, E. (2007). A new impetus to the CFP: Better governance, Better economics, European Commission XVIIIth EAFE Conference, sld. 3,4,56,7, Reykjavik.

Sabatella, E. \& Franquesa, R. (2003). Manual of fisheries sampling surveys: methodologies for estimations of socio-economic indicators in the Mediterranean Sea. Studies and Reviews. General Fisheries Commission for the Mediterranean. No. 73. Rome, FAO. 37p.

Şahin Özen, S. (2006). Tekirdă̆ ili deniz balıkçılığının sosyo- ekonomik durumu ve pazarlama yapısı (Yayımlanmamış Yüksek Lisans Tezi). Trakya Üniversitesi Fen Bilimleri Enstitüsü, Tarım Ekonomisi Anabilim Dalı, Edirne, 1-97.

Tietze, U., Prado, J., Le RY, J-M. and Lasch, R. (2001). Techno-economic performance of marine capture fisheries. FAO Fisheries Technical Paper, No: 421, $79 \mathrm{p}$.

Tzanatos, E., Dimitriou, E., Katselis, G., Georgiadis, M. \& Koutsikopolulos, C. (2005). Composition, Temporal Dynamics And Regional Characteristics Of Small-Scale Fisheries Ġn Greek. Fisheries Research 73: 147-158.
Uzmanoğlu, S. \& Soylu, M. 2006. Karasu (Sakarya) Bölgesi deniz balıkçılarının sosyo-ekonomik yapısı. E.Ü.Su Ürünleri Dergisi, 23(1/3), 515-518.

Ünal, V., Özekinci, U. \& Akyol, O. (1998). Foça trol balıkçılığının bugünkü durumu. Doğu Anadolu Bölgesi III. Su Ürünleri Sempozyumu, 10-12 Haziran 1998, Erzurum, Türkiye, 221-230.

Yamane, T. (2001). Temel örnekleme yöntemleri (A. Esin, C. Aydın, M. A. Bakır ve E. Gürbüzsel, Çevirenler), Literatür Yayınları, Yayın No: 53, İstanbul, $505 \mathrm{~s}$.

Yücel, Ş. (2006). Orta Karadeniz Bölgesi balıkçılığg ve balıkçıların sosyo-ekonomik durumu. E.Ü.Su Ürünleri Dergisi, 23(1/3), 529-532.

Received date: 31.01 .2018

Accepted date: 28.02 .2018

\section{*Corresponding author's:}

Doç. Dr. Cengiz MUTLU

Giresun Üniversitesi, Fen Edebiyat Fakültesi, Biyoloji Bölümü, TR-28200/Giresun, Turkey.

E-mail: cengiz.mutlu@giresun.edu.tr 